\title{
Endovascular Reconstruction of Intracranial Aneurysms with the Pipeline Embolization Device in Pediatric Patients: A Single-Center Series
}

\author{
Peyman Shirani $^{a}$ Saeedeh Mirbagheri ${ }^{b}$ Maksim Shapiro ${ }^{c} \quad$ Eytan Raz $^{c}$ \\ Ashkan Mowla $^{d}$ Bita Semsarieh ${ }^{a}$ Howard A. Riina ${ }^{c}$ Peter K. Nelson ${ }^{c}$ \\ ${ }^{a}$ Department of Neurology/Rehabilitation Medicine and Neurosurgery, University of \\ Cincinnati, Cincinnati, OH, USA; ${ }^{b}$ Department of Diagnostic Radiology, Mount Sinai Beth \\ Israel Medical Center, New York, NY, USA; ' Departments of Radiology and Neurology, \\ Bernard and Irene Schwartz Neurointerventional Radiology Section, New York University \\ School of Medicine, New York, NY, USA; dDepartment of Radiology, University of California, \\ Los Angeles, CA, USA
}

\section{Keywords}

Endovascular coiling · Intracranial aneurysm · Pediatric population · Pipeline Embolization Device - Pipeline

\begin{abstract}
Background: Pediatric intracranial aneurysms tend to differ in etiology, size, and location from their adult counterparts, and they are often less amenable to microsurgical clip reconstruction techniques. Endovascular treatment with detachable coils is an accepted treatment technique for pediatric patients, though high recurrence rates have been reported with coil embolization of large and giant aneurysms in this population. While the Pipeline Embolization Device (PED) is FDA-approved for adult intracranial aneurysms, the use of PEDs in pediatric patients is considered off-label. Case Descriptions: We present 3 cases of pediatric intracranial aneurysms in a 5-year-old male, a 12-year-old male, and a 12-year-old female who presented with symptoms including seizure, headache, and blurred vision. The 2 male patients were found to have intradural vertebral artery saccular aneurysms, while the female patient had a paraophthalmic right internal carotid complex aneurysm. After endovascular reconstruction of the aneurysms with PEDs, follow-up angiography showed complete occlusion of the previous aneurysms with no residual aneurysm filling in all 3 cases. Conclusion: While further investigation is needed, the evidence presented here supports the conclusion that the PED can be an effective and viable treatment strategy in the pediatric population.
\end{abstract}




\section{Introduction}

Intracranial aneurysms are uncommon in the pediatric population, occurring in only $0.5-4.6 \%$ of patients 18 years of age or younger $[1,2]$. Most aneurysmal risk factors in adults do not exist in pediatric patients. Pediatric patients also show different pathogenesis, demographics, and anatomical features for aneurysms, including male predominance, higher incidence in the posterior circulation, and a greater incidence of large and giant aneurysms. The initial presentations of most unruptured aneurysms in the pediatric population include headache, seizure, and mass effect [3]. Aneurysms in this population are often not amenable to direct microsurgical clip reconstruction techniques due to the predominance of unfavorable locations for surgical access [4, 5]. High recurrence rates following endovascular coiling also make traditional endovascular therapies less favored in pediatric patients [6, 7].

The Pipeline Embolization Device (PED) was approved by the FDA in 2011 for adult patients and has since been shown to provide higher aneurysm occlusion rates compared with preexisting endovascular techniques such as coiling and parent vessel occlusion, with comparable associated morbidity [8-10]. To date, however, there has been only one clinical trial comparing the efficacy and safety of endovascular coiling and clipping in children [11]. There have also been relatively few case reports on pediatric patients treated with flow diversion [3, 5, 12-14]. To illustrate the safety and efficacy of this relatively new endovascular technique in treating intracranial aneurysms in pediatric patients, we present in this article our experience in treating 3 pediatric aneurysm cases using the PED.

\section{Case Reports}

The 3 cases that will be discussed in this article are summarized in Table 1 . All patients were given aspirin (81 mg) and Plavix (0.2-1.0 mg/kg/day, maximum $75 \mathrm{mg} /$ day) for 5 days prior to the procedure. Platelet inhibition was measured using the P2Y12 assay. On the day of the procedure, the goal of P2Y12 reactivity between 50 and 150 was achieved. All of the procedures were performed under general endotracheal anesthesia.

Case 1

A 12-year-old male presented to the emergency department with neck stiffness of several weeks' duration. CT of the head showed a giant left vertebral artery aneurysm at the foramen magnum level. The patient was evaluated and scheduled for an elective cerebral angiogram and possible embolization and was discharged home. He later returned to the hospital with complaints of a headache and more severe neck pain than first reported. An MRI/MRA of the patient's head confirmed an approximately 2-cm aneurysm arising from the left vertebral artery proximal to the vertebrobasilar junction, which had enlarged since the prior CT study.

The patient was admitted and underwent cerebral angiography, demonstrating a giant partially thrombosed aneurysm originating from a distal left vertebral artery, without incorporation of the vertebrobasilar junction (Fig. 1). The left posterior inferior cerebellar artery originated just proximal to the aneurysmal segment. A left lateral medullary perforator (bulbar artery) originated $7 \mathrm{~mm}$ proximal to the aneurysmal segment. Other than the symptoms of a severe headache and neck pain, the patient's history and neurological examination were unremarkable.

To treat this patient, a 4-gauge French sheath was placed in the right femoral artery, and diagnostic angiography was performed using 4-gauge French diagnostic catheters. The diagnostic catheter and sheath were then exchanged for a 088 Neuron Max guide catheter. The aneurysm was selectively catheterized using an Echelon-10 microcatheter. The aneurysm neck was then crossed with a Marksman microcatheter, which was advanced into the distal basilar artery. The aneurysmal segment of the left vertebral artery was reconstructed with five overlapping PEDs, telescopically deployed from proximal to distal across the aneurysm neck, in such a way that the proximal perforator and the vertebrobasilar junction were preserved. Once the pipeline reconstruction was completed, the aneurysm fundus was coiled with multiple detachable platinum coils. This final step was based on growing evidence in the IntrePED database supporting the addition of coils for large and giant aneurysms [15]. Since treatment with the PED takes a few months to fully secure the 


\section{Interventional Neurology}

Fig. 1. Pipeline embolization of a left vertebral artery aneurysm. a Left vertebral injection, oblique view, showing a distal intracranial left vertebral artery aneurysm, $1.2 \mathrm{~cm}$ proximal to the vertebrobasilar junction, measuring $2.4 \times$ $1.6 \mathrm{~cm}$, with a neck size of $1.9 \mathrm{~cm}$. b Native image, lateral view, after telescopic deployment of five overlapping PEDs, showing the proximal and distal ends of the PEDs (arrows). c Left vertebral angiogram, post PED reconstruction and coiling, showing complete occlusion of the aneurysm. d A 6-month follow-up diagnostic angiography demonstrated complete occlusion of the aneurysm with no residual aneurysm filling. PED, Pipeline Embolization Device.

\begin{tabular}{l|l}
\hline Intervent Neurol 2019;8:101-108 \\
\hline DOI: 10.1159/000496291 & $\begin{array}{l}\text { @ 2019 S. Karger AG, Basel } \\
\text { www.karger.com/ine }\end{array}$ \\
\hline
\end{tabular}

Shirani et al.: Endovascular Reconstruction of Intracranial Aneurysms in Pediatrics
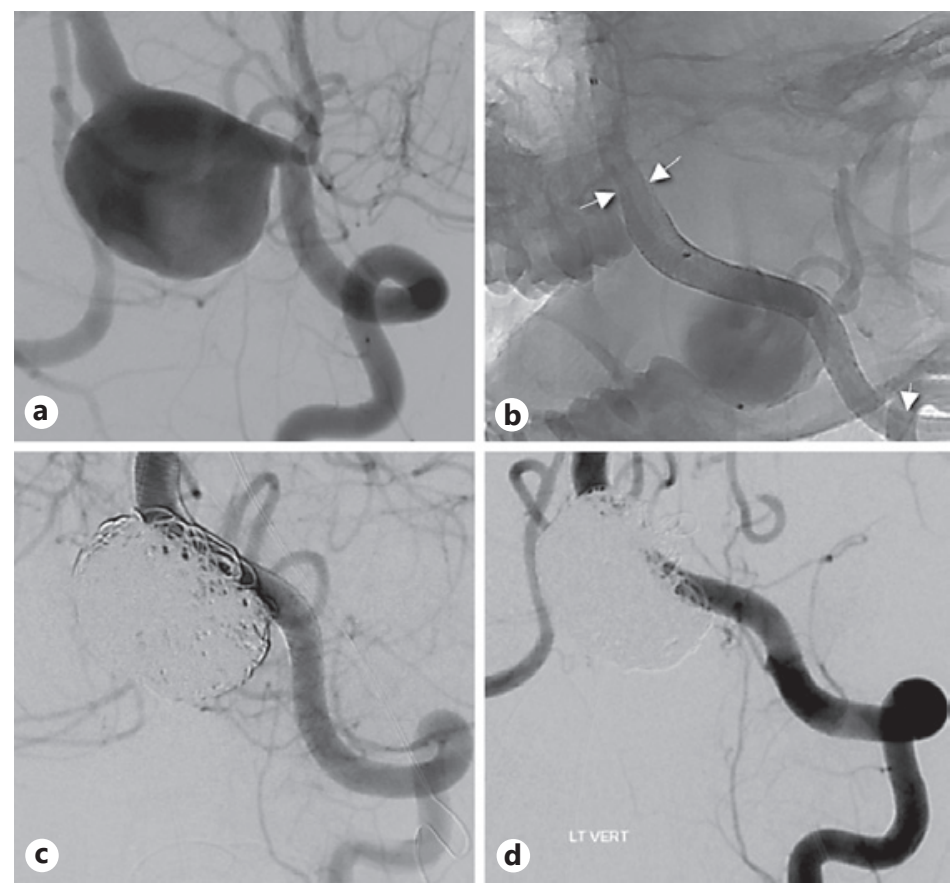

Table 1. Case summaries

\begin{tabular}{|c|c|c|c|c|c|c|}
\hline Patient & Symptoms & $\begin{array}{l}\text { Aneurysm } \\
\text { location }\end{array}$ & $\begin{array}{l}\text { Aneurysm } \\
\text { size }\end{array}$ & Aneurysm morphology & PEDs/coils & Follow-up \\
\hline $\begin{array}{l}\text { Case } 1 \\
\text { 12-year- } \\
\text { old male }\end{array}$ & $\begin{array}{l}\text { headache, } \\
\text { neck } \\
\text { stiffness }\end{array}$ & $\begin{array}{l}\text { intradural } \\
\text { left } \\
\text { vertebral }\end{array}$ & $\begin{array}{l}24 \times 16 \mathrm{~mm} \\
\text { with a neck size } \\
\text { of } 19 \mathrm{~mm}\end{array}$ & saccular aneurysm & $\begin{array}{l}5 \text { PEDs plus } \\
\text { coiled } \\
\text { aneurysm }\end{array}$ & $\begin{array}{l}\text { 6-month DSA } \\
\text { showed no } \\
\text { residual } \\
\text { aneurysm } \\
\text { filling }\end{array}$ \\
\hline $\begin{array}{l}\text { Case } 2 \\
\text { 12-year- } \\
\text { old female }\end{array}$ & $\begin{array}{l}\text { headache, } \\
\text { blurred } \\
\text { vision }\end{array}$ & $\begin{array}{l}\text { right ICA } \\
\text { paraoph- } \\
\text { thalmic to } \\
\text { terminus }\end{array}$ & $1.2 \mathrm{~cm}$ & $\begin{array}{l}\text { complex dysplastic distal } \\
\text { ICA involving origin of } \\
\text { PCOM, MCA, and ACA; } \\
\text { accessory MCA arising from } \\
\text { A1 distal to aneurysm }\end{array}$ & 4 PEDs & $\begin{array}{l}\text { 8-month DSA } \\
\text { showed no } \\
\text { residual } \\
\text { aneurysm } \\
\text { filling }\end{array}$ \\
\hline $\begin{array}{l}\text { Case } 3 \\
\text { 5-year- } \\
\text { old male }\end{array}$ & seizure & $\begin{array}{l}\text { intradural } \\
\text { left } \\
\text { vertebral }\end{array}$ & $\begin{array}{l}7 \times 4 \mathrm{~mm} \text { with } \\
\text { a neck size of } \\
7 \mathrm{~mm}\end{array}$ & saccular aneurysm & 2 PEDs & $\begin{array}{l}\text { 1-year DSA } \\
\text { showed no } \\
\text { residual } \\
\text { aneurysm } \\
\text { filling }\end{array}$ \\
\hline
\end{tabular}

ACA, anterior cerebral artery; DSA, digital subtraction angiography; ICA, internal carotid artery; MCA, middle cerebral artery; PCOM, posterior communicating artery; PEDs, Pipeline Embolization Devices. 


\section{Interventional Neurology}

Fig. 2. Pipeline embolization of a right ICA aneurysm. a Right ICA angiogram, anteroposterior view, demonstrating a complex dysplasia of the supraclinoid segment of the right ICA associated with a fusiform aneurysm. b Native image, oblique view, after telescopic deployment of four overlapping PEDs, shows the proximal ends (thin arrow) and distal ends (thick arrow) of the PEDs. c Anteroposterior view angiogram of right ICA post PED deployment showing the proximal ends (arrowhead) and distal ends (thin arrows) of the PEDs. d An 8-month follow-up diagnostic angiography demonstrated complete occlusion of the aneurysm with no residual aneurysm filling. ICA, internal carotid artery; PED, Pipeline Embolization Device.

\begin{tabular}{l|l}
\hline Intervent Neurol 2019;8:101-108 \\
\hline DOI: 10.1159/000496291 & $\begin{array}{l}\text { C 2019 S. Karger AG, Basel } \\
\text { www.karger.com/ine }\end{array}$ \\
\hline
\end{tabular}

Shirani et al.: Endovascular Reconstruction of Intracranial Aneurysms in Pediatrics
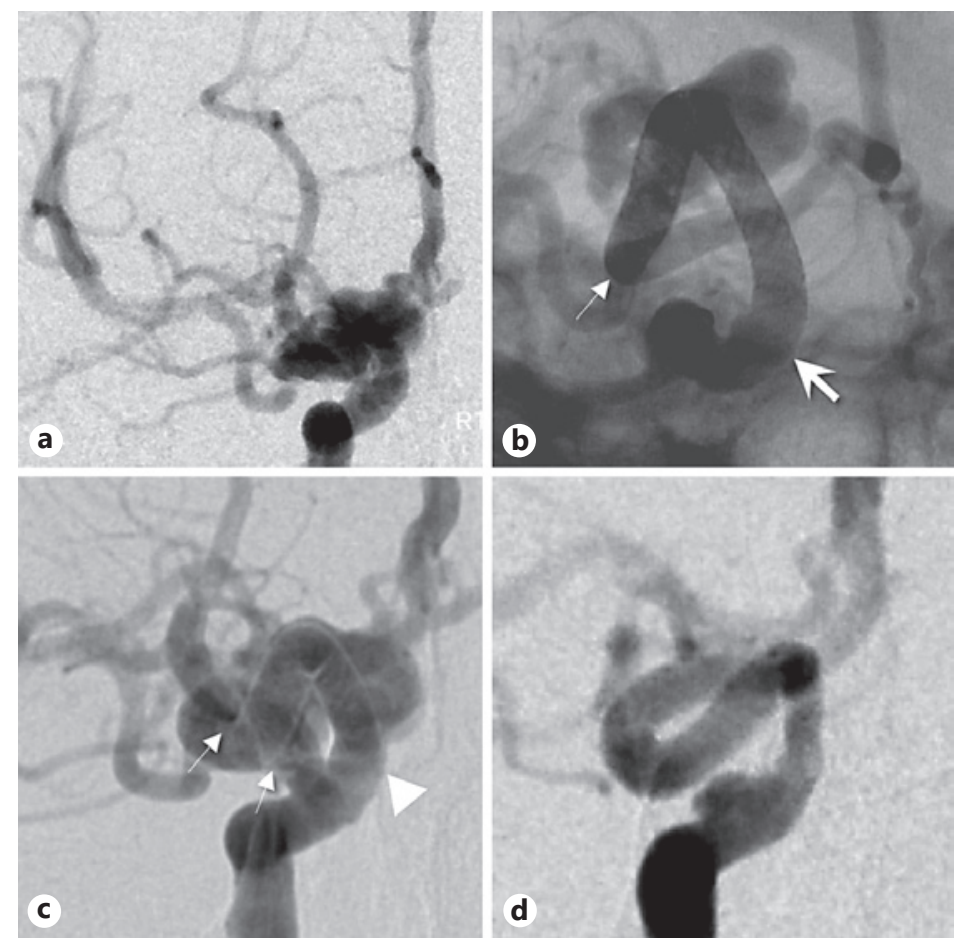

aneurysm, coiling on top of the PED is done in order to secure the aneurysm faster, especially with warning signs such as growth of the aneurysm.

At the 6-month follow-up, the patient was neurologically intact and was taking aspirin (81 mg) and Plavix (50 mg) daily. His 6-month follow-up angiography demonstrated complete occlusion of the previously known left vertebral artery aneurysm, without residual aneurysmal dome filling.

\section{Case 2}

A 12-year-old female presented to the emergency department complaining of frontal and left occipital headache lasting 1 week and a 1-h episode of blurred vision. The initial head MRI/MRA showed a complex aneurysm arising from the terminus segment of the right internal carotid artery (ICA). The patient underwent elective cerebral angiography that demonstrated a complex dysplastic segment of the distal ICA associated with a fusiform aneurysm of the supraclinoid segment of the right ICA. The patient's past medical history and physical examination were otherwise unremarkable.

Diagnostic angiography was performed using a 5-gauge French diagnostic catheter that was then exchanged for a 6-gauge French Neuron Max guiding catheter over an exchange-length wire. The tip of the guiding catheter was positioned within the bulb of the ICA. A 5-gauge French Navien catheter was placed in the horizontal petrosal segment of the ICA. Subsequently, using roadmap guidance, a Marksman catheter was positioned using a 0.014 Transend wire into the A1 segment of the right anterior cerebral artery. The aneurysms and dysplastic segment were treated using a partially overlapping construct of four PEDs, spanning the A1 to cavernous segments, in the setting of an accessory middle cerebral artery variant (Fig. 2).

At the 8-month follow-up, the patient was neurologically intact and was taking aspirin (81 mg) and Plavix (50 mg) daily. Her 8-month follow-up angiography demonstrated complete occlusion of the previous complex aneurysm of the distal right ICA, without residual aneurysm filling. There was also reconstruction of the dysplastic segment.

Case 3

A 5-year-old male with a history of tuberous sclerosis, seizures, and cardiac rhabdomyoma was found to have a left-sided vertebral artery aneurysm during a tuberous sclerosis workup. He was electively admitted for a diagnostic cerebral angiogram. After discussion with the referring physician, the decision was made to perform pipeline embolization of the left vertebral aneurysm. 

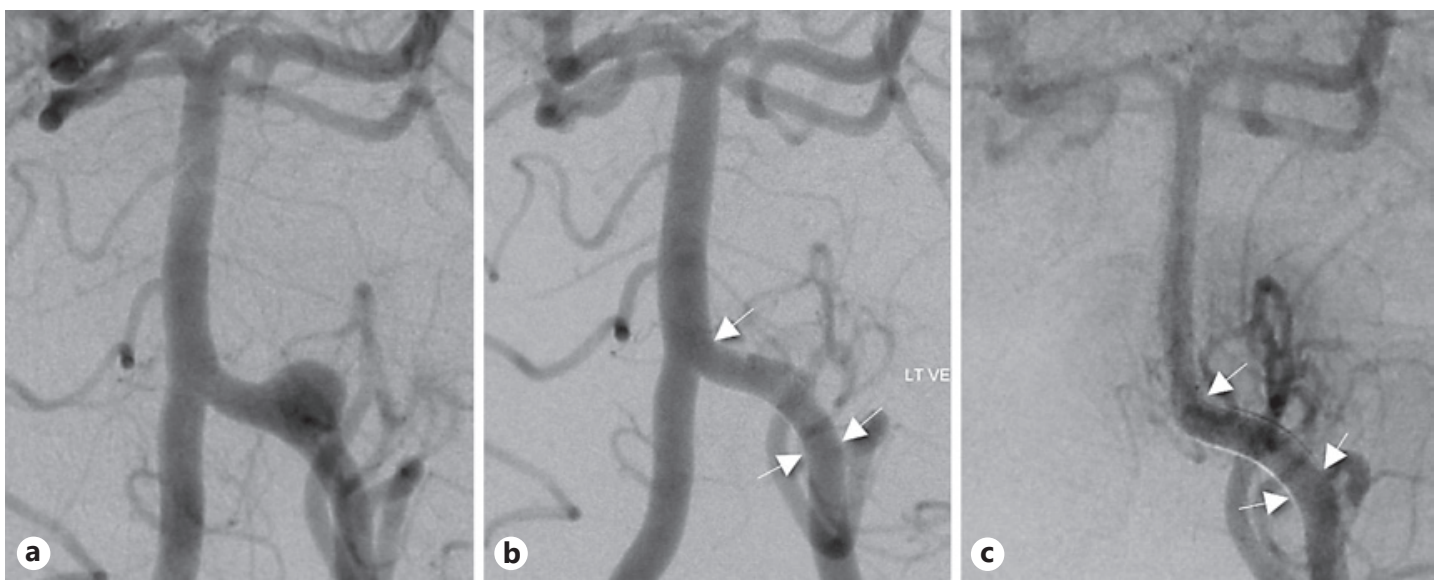

Fig. 3. Pipeline embolization of a left vertebral artery aneurysm. a Left vertebral angiogram, anteroposterior view, demonstrating a wide neck distal intracranial left vertebral artery aneurysm. b Anteroposterior view angiogram of the left vertebral artery after the deployment of two PEDs, with arrows showing the proximal and distal ends of the PEDs. c A 1-year follow-up diagnostic angiography examination shows complete elimination of a previous aneurysm and no residual aneurysm filling. PED, Pipeline Embolization Device.

A diagnostic angiogram was performed using a 5-gauge French Envoy catheter. Following angiographic evaluation, the aneurysm was crossed with a 0.014 Transend guidewire over which a 2.8-French Marksman microcatheter was advanced past the aneurysm and into the basilar artery. The catheter was positioned with its distal tip just proximal to the basilar artery. The aneurysm was subsequently treated by placing two overlapping PEDs (Fig. 3).

At the 1-year follow-up, the patient was neurologically intact and was taking aspirin (81 $\mathrm{mg}$ ) and Plavix (25 mg) daily. The 1-year follow-up angiogram did not demonstrate any residual aneurysm filling.

\section{Discussion}

Pediatric intracranial aneurysms are rare lesions, representing only about $1.0-4.6 \%$ of all reported intracranial aneurysms $[12,16]$. The long life expectancy of most children and the associated disability-adjusted life years among this population necessitate a form of treatment that demonstrates both high obliteration and low recurrence rates. Up to $40 \%$ of all pediatric intracranial aneurysms are giant ( $>25 \mathrm{~mm}$ in diameter), and up to $51 \%$ exhibit fusiform/dolichoectatic morphologic features [17, 18]. Researchers have reported that among the $42 \%$ of pediatric aneurysms involving the posterior circulation, $32 \%$ were in the posterior cerebral artery, and that among the $58 \%$ of pediatric aneurysms involving the anterior circulation, $26 \%$ were at the terminal and cavernous portion of the ICA [18]. Thus, the frequency of intracranial aneurysms not amenable to open surgery or coil occlusion is quite high in pediatric patients.

Studies have shown more favorable outcomes after coil embolization, compared with open surgery, for aneurysms involving the posterior circulation [19]. Furthermore, aneurysms in the cavernous segment of the ICA, which are often difficult to treat with microsurgery, can readily be approached by endovascular methods [19]. Endovascular treatment of aneurysms is associated with lower mortality compared to microsurgical clipping in the pediatric population [20].

Back in 2003, after conducting an 11-year follow-up study of 916 coiled aneurysms, Murayama et al. [21] found that aneurysm size and morphology were the critical variables 
leading to incomplete initial occlusion and later recurrence in endovascularly treated aneurysms. This study also found that in giant aneurysms, incomplete coiling occurred in $63 \%$ of cases, with a recurrence rate of $60 \%$ of incompletely coiled and $42 \%$ of completely coiled aneurysms. Other researchers found that endovascularly treated pediatric aneurysms with coiling had significantly higher rates of recurrence and formation of de novo aneurysms compared to a surgical cohort that underwent microsurgical treatment [22]. In addition, a large coil mass was associated with continued mass effect in large and giant intracranial aneurysms, leading to devastating neurological deficits [4]. The PED was developed to help with these problems and to improve the effectiveness of endovascular treatment. The Pipeline for Uncoilable or Failed Aneurysms (PUFS) trial demonstrated the safe and effective use of the PED in the treatment of large and giant anterior circulation intracranial ICA aneurysms, evidenced by low permanent morbidity or mortality $(5.6 \%)$ and high rates of complete aneurysm occlusion, with durable results now demonstrated up to 5 years post treatment $[16,23]$.

The use of PEDs to treat intracranial aneurysms was approved by the FDA for adults in 2011. However, there is not as much accumulated evidence for the use of this approach in pediatric patients, where it is still considered an off-label treatment. The cases presented here make an important contribution to this needed evidence. All of the cases involved complex lesions located in the distal vertebral artery and the supraclinoid segment of the ICA. All were felt to be difficult surgical cases and either not amenable to coil occlusion or at high risk for recurrence with existing coil or stent-coil methods [24]. Thus, a PED approach was selected based on the apparent durability of pipeline-based vessel reconstruction, resulting in endothelialization of the neolumen and long-term aneurysm exclusion from parent circulation $[25,26]$.

Pipeline embolization has several potential advantages, especially in the pediatric population. The risk of intraoperative blood loss is considerably less when using endovascular methods for small children. Other advantages include relatively straightforward access to all vascular locations, less dependency on a large coil volume, and the ability to reconstruct whole vascular segments without the need for parent vessel occlusion. However, there are also some limitations. Pipeline embolization requires a largely empiric dual antiplatelet regimen, which in young, active children might be problematic. Moreover, if PED treatment fails, the low porosity of the device construct may preclude access to an aneurysm for further coiling. This can limit downstream options to vessel sacrifice, with or without bypass. It is also still unclear how exactly PED treatments will adjust to vessel growth in children.

While the findings of the current study are extremely promising, additional research needs to be carried out beyond these 3 cases. More long-term studies are also needed. Our patients' aneurysms were reconstructed using two to five overlapping PEDs per aneurysm, and followup diagnostic angiographies up to 1 year following the procedures demonstrated complete occlusion of the aneurysms and no residual filling defects. Future studies will need to investigate additional PED procedures in pediatric patients and to examine long-term complication and regrowth rates beyond 1 year. At the current time we can say that surgical management and endovascular coiling are likely to remain the major treatment strategies in the armamentarium of pediatric neurosurgeons and neurointerventionists, but PED treatment should be considered as a robust alternative for the occlusion of large to giant pediatric aneurysms.

\section{Conclusion}

Pediatric intracranial aneurysms are more amenable to endovascular therapies compared to microsurgical constructive and deconstructive techniques. Endovascular coiling treatments lead to a high recurrence rate in pediatric aneurysms. Moreover, the mass effect exerted 
on adjacent vital structures from a giant coiled aneurysm can lead to continued or worsening neurological deficits. Pipeline embolization may be a more effective treatment for completely eliminating aneurysms and reconstructing dysplastic vascular segments in the pediatric population. This article presented 3 cases of pediatric patients who were successfully treated using PEDs, thus demonstrating the potential value of the PED approach. The evidence for the success of PED treatment as an alternative to currently available therapeutic strategies for appropriately selected pediatric cerebral aneurysms warrants further investigation with long-term follow-up.

\section{Statement of Ethics}

The authors would like to state that subjects or their legal parents have given their informed consent and that the study protocol was approved by the institute's committee on human research. No animals were involved.

\section{Disclosure Statement}

The authors declare that they have no competing interests. This research received no specific grant from any funding agency in the public, commercial, or not-for-profit sectors.

\section{References}

1 Jian BJ, Hetts SW, Lawton MT, Gupta N. Pediatric intracranial aneurysms. Neurosurg Clin N Am. 2010 Jul;21(3): 491-501.

2 Kakarla UK, Beres EJ, Ponce FA, Chang SW, Deshmukh VR, Bambakidis NC, et al. Microsurgical treatment of pediatric intracranial aneurysms: long-term angiographic and clinical outcomes. Neurosurgery. 2010 Aug; 67(2):237-49; discussion 250.

3 Ikeda DS, Marlin ES, Shaw A, Powers CJ. Successful endovascular reconstruction of a recurrent giant middle cerebral artery aneurysm with multiple telescoping flow diverters in a pediatric patient. Pediatr Neurosurg. 2015;50(2):88-93.

4 Halbach VV, Higashida RT, Dowd CF, Barnwell SL, Fraser KW, Smith TP, et al. The efficacy of endosaccular aneurysm occlusion in alleviating neurological deficits produced by mass effect. J Neurosurg. 1994 Apr;80(4): 659-66.

5 Navarro R, Brown BL, Beier A, Ranalli N, Aldana P, Hanel RA. Flow diversion for complex intracranial aneurysms in young children. J Neurosurg Pediatr. 2015 Mar;15(3):276-81.

6 Krishna H, Wani AA, Behari S, Banerji D, Chhabra DK, Jain VK. Intracranial aneurysms in patients 18 years of age or under, are they different from aneurysms in adult population? Acta Neurochir (Wien). 2005 May; 147(5):469-76; discussion 476.

7 Sanai N, Quinones-Hinojosa A, Gupta NM, Perry V, Sun PP, Wilson CB, et al. Pediatric intracranial aneurysms: durability of treatment following microsurgical and endovascular management. J Neurosurg. 2006 Feb;104 (2 Suppl):82-9.

8 Chalouhi N, Tjoumakaris S, Starke RM, Gonzalez LF, Randazzo C, Hasan D, et al. Comparison of flow diversion and coiling in large unruptured intracranial saccular aneurysms. Stroke. 2013 Aug;44(8):2150-4.

9 Kallmes DF, Brinjikji W, Boccardi E, Ciceri E, Diaz O, Tawk R, et al. Aneurysm Study of Pipeline in an Observational Registry (ASPIRe). Intervent Neurol. 2016 Jun;5(1-2):89-99.

10 Kallmes DF, Brinjikji W, Cekirge S, Fiorella D, Hanel RA, Jabbour P, et al. Safety and efficacy of the Pipeline embolization device for treatment of intracranial aneurysms: a pooled analysis of 3 large studies. J Neurosurg. 2017 Oct;127(4):775-80.

11 Agid R, Souza MP, Reintamm G, Armstrong D, Dirks P, TerBrugge KG. The role of endovascular treatment for pediatric aneurysms. Childs Nerv Syst. 2005 Dec;21(12):1030-6.

12 Burrows AM, Zipfel G, Lanzino G. Treatment of a pediatric recurrent fusiform middle cerebral artery (MCA) aneurysm with a flow diverter. J Neurointerv Surg. 2013 Nov;5(6):e47.

13 Vachhani JA, Nickele CM, Elijovich L, Klimo P, Arthur AS. Flow Diversion for Treatment of Growing A2 Aneurysm in a Child: Case Report and Review of Flow Diversion for Intracranial Aneurysms in Pediatric Patients. World Neurosurg. 2016 Dec;96:607.e13-7. 
14 Vargas SA, Diaz C, Herrera DA, Dublin AB. Intracranial Aneurysms in Children: The Role of Stenting and FlowDiversion. J Neuroimaging. 2016 Jan-Feb;26(1):41-5.

15 Park MS, Kilburg C, Taussky P, Albuquerque FC, Kallmes DF, Levy EI, et al. Pipeline Embolization Device with or without Adjunctive Coil Embolization: Analysis of Complications from the IntrePED Registry. AJNR Am J Neuroradiol. 2016 Jun;37(6):1127-31.

16 Becske T, Brinjikji W, Potts MB, Kallmes DF, Shapiro M, Moran CJ, et al. Long-Term Clinical and Angiographic Outcomes Following Pipeline Embolization Device Treatment of Complex Internal Carotid Artery Aneurysms: Five-Year Results of the Pipeline for Uncoilable or Failed Aneurysms Trial. Neurosurgery. 2017 Jan;80(1): $40-8$.

17 Fulkerson DH, Voorhies JM, Payner TD, Leipzig TJ, Horner TG, Redelman K, et al. Middle cerebral artery aneurysms in children: case series and review. J Neurosurg Pediatr. 2011 Jul;8(1):79-89.

18 Huang J, McGirt MJ, Gailloud P, Tamargo RJ: Intracranial aneurysms in the pediatric population: case series and literature review. Surg Neurol. 2005 May;63(5):424-32; discussion 432-3.

19 Gruber DP, Zimmerman GA, Tomsick TA, van Loveren HR, Link MJ, Tew JM Jr. A comparison between endovascular and surgical management of basilar artery apex aneurysms. J Neurosurg. 1999 May;90(5):868-74.

20 Alawi A, Edgell RC, Elbabaa SK, Callison RC, Khalili YA, Allam H, et al. Treatment of cerebral aneurysms in children: analysis of the Kids' Inpatient Database. J Neurosurg Pediatr. 2014 Jul;14(1):23-30.

21 Murayama Y, Nien YL, Duckwiler G, Gobin YP, Jahan R, Frazee J, et al. Guglielmi detachable coil embolization of cerebral aneurysms: 11 years' experience. J Neurosurg. 2003 May;98(5):959-66.

22 Saraf R, Shrivastava M, Siddhartha W, Limaye U. Intracranial pediatric aneurysms: endovascular treatment and its outcome. J Neurosurg Pediatr. 2012 Sep;10(3):230-40.

23 Becske T, Kallmes DF, Saatci I, McDougall CG, Szikora I, Lanzino G, et al. Pipeline for Uncoilable or Failed Aneurysms: results from a multicenter clinical trial. Radiology. 2013 Jun;267(3):858-68.

24 Shapiro M, Becske T, Sahlein D, Babb J, Nelson PK. Stent-supported aneurysm coiling: a literature survey of treatment and follow-up. AJNR Am J Neuroradiol. 2012 Jan;33(1):159-63.

25 Alderazi YJ, Shastri D, Kass-Hout T, Prestigiacomo CJ, Gandhi CD. Flow diverters for intracranial aneurysms. Stroke Res Treat. 2014;2014:415653.

26 Fiorella D, Lylyk P, Szikora I, Kelly ME, Albuquerque FC, McDougall CG, et al. Curative cerebrovascular reconstruction with the Pipeline embolization device: the emergence of definitive endovascular therapy for intracranial aneurysms. J Neurointerv Surg. 2009 Jul;1(1):56-65. 